\title{
Extracurricular Factors Influence Perceived Stress in a Large Cohort of Colombian Dental Students
}

\author{
Kimon Divaris, D.D.S., Ph.D.; Argy Polychronopoulou, D.D.S., M.S., Sc.M., Sc.D.; Laura \\ Villa-Torres, B.A., M.S.P.H.; Ana Cristina Mafla, D.D.S., M.S.P.H.; Gloria Aranzazu Moya, \\ D.D.S.; Farith González-Martínez, D.D.S., M.S.P.H.; Luis Armando Vila-Sierra, D.D.S., \\ M.S., Ph.D.; Natalia Fortich-Mesa, D.D.S., M.S.C.E.; Ruth Ángela Gómez-Scarpetta, \\ B.A.C.T.; Liliana María Duque-Restrepo, D.D.S.
}

\begin{abstract}
The aim of this study was to investigate the association of extracurricular factors including socioeconomic status and career choice with perceived stress in dental school in a large cohort of Colombian dental students. Participants in the study were 5,700 students enrolled in seventeen Colombian dental schools. The study employed a Spanish adaptation of the Dental Environment Stressors (DES30-Sp) questionnaire and recorded an array of demographic, socioeconomic, career choice, and dental studies-related information. Data analyses relied on descriptive, bivariate, and multivariate methods based on multi-level mixed-effects linear regression and post hoc estimation of predictive margins. "Fear of failing a course or year" emerged as the highest ranked item. Male students consistently reported less perceived stress than females, and stress scores were higher among seniors. Independent of gender, age, and study year, having dentistry as one's first career choice, relying on financial support, and belonging to higher socioeconomic strata were associated with lower stress levels. Academic environment interventions aimed to improve students' educational well-being will need to account for the individual heterogeneity among them. These data from a robust cohort of predoctoral dental students underscore the importance of considering students' educational experiences in a broader social and economic context.
\end{abstract}

Dr. Divaris is Research Assistant Professor, Department of Pediatric Dentistry, School of Dentistry, University of North Carolina at Chapel Hill, United States; Dr. Polychronopoulou is Associate Professor, Department of Preventive and Community Dentistry, University of Athens School of Dentistry, Athens, Greece; Ms. Villa-Torres is a Ph.D. candidate, Department of Health Behavior, Gillings School of Global Public Health, University of North Carolina at Chapel Hill, United States; Dr. Mafla is Research Assistant Professor and Dentistry Research Group Director, Universidad Cooperativa de Colombia-Pasto School of Dentistry, Pasto, Colombia; Dr. Aranzazu Moya is Research Professor and Salud Integral Bucal (SIB) Research Group member, Universidad Santo Tomás Bucaramanga School of Dentistry, Bucaramanga, Colombia; Dr. González-Martínez is Research Assistant Professor, Universidad de Cartagena School of Dentistry, Cartagena, Colombia; Dr. Vila-Sierra is Research Assistant Professor and Family Dental Health Research Department Director, Universidad de Magdalena School of Dentistry, Santa Marta, Colombia; Dr. Fortich-Mesa is Research Professor and Community Dental Health Research Group Director, Corporación Universitaria Rafael Núñez School of Dentistry, Cartagena, Colombia; Ms. Gómez-Scarpetta is Research Assistant Professor and Dentistry Research Group Director, Universidad Cooperativa de Colombia-Villavicencio School of Dentistry, Villavicencio, Colombia; and Dr. Duque-Restrepo is Associate Professor, Universidad Autónoma de Manizales School of Dentistry, Manizales, Colombia. Direct correspondence and requests for reprints to Dr. Kimon Divaris, 228 Brauer Hall, Department of Pediatric Dentistry, School of Dentistry, CB\#7450, University of North Carolina, Chapel Hill, NC 27599-7450; 919-537-3556; divarisk@dentistry.unc.edu.

Keywords: stress, dental education, dental students, socioeconomic factors, career choice, gender differences, Colombia

Submitted for publication 12/20/12; accepted 3/12/13

$\mathrm{T}$ Training to become a dentist is a complex and demanding pedagogical process wherein, during a four- to five-year curriculum, young trainees are expected to attain a markedly diverse set of competencies. During their training, predoctoral dental students develop and hone a plethora of clinical, theoretical, critical thinking, and interpersonal skills while functioning in overcrowded schedules. ${ }^{1}$ At the same time, student concerns are often articulated regarding weaknesses of certain aspects of dental curricula, including inefficient learning environments, poor instructional quality, methods of teaching, and assessment. ${ }^{2-4}$ Dental students' response to and coping with the demands and issues encountered in dental school are not always optimal. Evidence shows that certain groups of students feel overwhelmed by their experience in dental school to the extent that their physical and mental health as well as their social life is negatively affected. ${ }^{5,6}$ Moreover, reports indicate that alarmingly high proportions of the student population may exhibit signs of burnout. ${ }^{7-9}$ 
Prolonged or intense perceived stress while in dental school can negatively impact the students' emotional, physical, social, and future professional well-being ${ }^{10}$ and thus does not facilitate optimal learning. Nevertheless, some stressors are inherent in dental education, and perhaps some stress can be beneficial for learning. However, in the presence of personality traits such as perfectionism, the impostor phenomenon, ${ }^{11}$ and type A personality ${ }^{12}$ that are important predisposing factors for psychological morbidity, the effect of these stressors can become magnified and detrimental. Other personal characteristics and their interaction with the dental school, peer, family, and social environment ${ }^{13-16}$ are undoubtedly important determinants of students' stress and maladaptive responses, ${ }^{6,13}$ but an ideal educational environment should be designed to accommodate different personalities and other individual characteristics. ${ }^{3,4}$

Considerable work examining the main sources and correlates of dental students' stress has been carried out during the last three decades ${ }^{17}$ Studies of dental students' sources of stress have typically examined the perceived importance of certain dental education-specific stress-provoking factors, such as examinations, patient care, time constraints, and others. This body of literature has provided valuable insights into curricular and broader educational aspects that shape and influence the actual and perceived academic environment. ${ }^{3,4}$ Muirhead and Locker ${ }^{15}$ reported that the use of social support systems by dental students had a protective, stressalleviating effect. Recently, Schéle et al. ${ }^{16}$ offered a psychosocial perspective of stress and satisfaction among Swedish dental students. Specifically, they suggested that large proportions of perceived stress may be attributed to the students' psychosocial work environment, which may be perceived differently by males and females. Satisfaction with career choice is another extracurricular factor consistently shown to be associated with students' stress-coping skills and perceptions. ${ }^{18,19}$ In sum, these studies have advanced the current state of knowledge by considering extracurricular, "real-life" parameters as correlates of dental students' perceived stress.

To date, little attention has been paid to the socioeconomic context and other distal factors that frame dental students' experiences and outcomes while in dental school. Gallo and Matthews ${ }^{20}$ have offered a theoretical framing that supports the possible role of socioeconomic factors in students' perceived stress. In their conceptual model, these authors outlined how the socioeconomic environment may condition and shape the "reserve capacity" or one's stress-dampening resources. While multiple and complex pathways may be at play in the association, emotional and cognitive factors, as well as previous stressful experiences, appear to have a prominent role in one's ability to cope with stress.

While most evidence on this topic has emanated from studies in Europe, North America, and Asia, data from Latin American countries are sparse. There are no data supporting an a priori hypothesis of systematic differences between Colombian and North American, European, African, or Asian dental students; however, we suggest that the underrepresentation of Latin American countries in the relevant literature provides support to the reporting of data from that region in the peer-reviewed literature. The aims of this study were to examine the perceived sources of stress in a large cohort of Colombian dental students and to investigate the association of extracurricular factors including demographic, socioeconomic, and dental studies-related parameters with several stress dimensions.

\section{Materials and Methods}

Dental students from seventeen dental schools in Colombia participated in a survey coordinated by the dental research group of the Universidad Cooperativa de Colombia in Pasto (UCC-Pasto) between January and April 2012. The study was approved by the Health Sciences Ethics Committee of the UCC-Pasto, and students' participation was voluntary. A detailed description of the study population, survey methodology, and procedures was reported in a previous article..$^{21}$ In brief, during the academic year 2011-12 there were a total of thirtythree Colombian dental schools with approximately 14,000 students. Most of these schools are private and operate a five-year lecture-based curriculum. Dental school admissions in Colombia are based on a combination of standardized tests and an interview process. Summative assessments are derived from a competitive and intensive nationwide examination administered by ICFES (Instituto Colombiano para el Fomento de la Educación Superior [Colombian Institute for the Promotion of Higher Education]) that is similar to the SAT (Scholastic Assessment Test) in the United States. The ICFES examination can be taken by students prior to graduation from high school, in the tenth or eleventh grade, and can 
be repeated as many times as the applicant chooses. In addition, Colombian dental schools generally conduct applicant interviews to aid in the selection of each first-year class.

The study investigators invited all students officially enrolled and attending classes in seventeen schools $(n=8,530)$ to participate in the study, and 5,700 students accepted for a response rate of 67 percent. The response rate varied between schools and ranged between a minimum of $\sim 40$ percent in the schools of UNAL-Bogotá and UAM-Manizales to 100 percent in the schools of UCC-Pasto, CURNCartagena, and UMET-Barranquilla. The study's analytical sample was not a random or probability sample of all Colombian dental students; however, it represents more than 60 percent of the total student population in the 2011-12 academic year.

\section{Instruments and Variables}

The study instrument was administered to the participating students in paper and pencil format and required about twenty-five minutes for completion. The DES30-Sp that was used to assess perceived sources of stress in this study is a Spanish adaptation ${ }^{22}$ of a modified Dental Environment Stressors (DES) questionnaire. ${ }^{23,24}$ The DES was first introduced by Garbee et al. ${ }^{25}$ and was subsequently modified by Westerman et al. ${ }^{26}$ and other investigators. The current instrument contains thirty items pertaining to dental education environment stressors that the students rate on a four-level scale according to their perceived stress-provoking potential: $1=$ not stressful at all, 2=somewhat stressful, $3=$ quite stressful, and $4=$ very stressful. Some of these stressors are "amount of assigned class work," "examinations and grades," "lack of time for relaxation," and "patients being late or not showing up for their appointments." As recently reported by Fonseca et al., ${ }^{22}$ the adaptation in Spanish language and psychometric evaluation of the instrument were performed among a group of approximately 300 Chilean and Argentinean dental students. Specifically, the DES30-Sp was found to have good psychometric properties (Cronbach's alpha $=0.89$ ) and a four-factor underlying structure. However, the investigators recommended further evaluation of the DES30-Sp among diverse and larger student samples to confirm its factor structure and psychometric properties.

Additional information was collected via the study questionnaire for demographic, socioeconomic, and dental studies-related factors. These were gender (female/male); age (measured in years and categorized into four groups: under eighteen, eighteen to twenty, twenty-one to twenty-three, and twenty-four and older); socioeconomic level (measured on a scale of 1-6 where $1=$ lowest and $6=$ highest and categorized into four groups: 1-2, 3, 4, and 5-6); funding sources for dental studies (measured in three categories: $1=$ own sources only, $2=$ own sources and loans, and $3=$ loans only); working while studying (working/ not working); marital status (married/not married); study year (first through fifth); self-report of having passed all required courses up to the current study level (yes/no); and having dentistry as one's first career choice (yes/no).

\section{Analytical Strategy}

Descriptive and bivariate methods were used for initial data exploration and presentation. Participants ( $\mathrm{n}=64,1$ percent of total) with substantial missing information ( $>6$ items) in the DES30-Sp questionnaire were excluded from the analytical sample. Missing values were rare: less than 1 percent for all items except "lack of home atmosphere in the living quarters" (11 percent) and "working while studying" (1 percent). Multiple imputation ${ }^{27}$ of missing values for all DES30-Sp items was performed, accounting for school, gender, study year, socioeconomic stratum, and first career choice. A global stress score represented by the mean of all DES30-Sp items was generated for each study participant as a measure of overall perceived stress. However, consistent with previous investigation, ${ }^{22}$ the examination of the factor structure of the instrument was based on principal factor analysis with promax ${ }^{28}$ (oblique) rotation and subsequent inspection of the corresponding Scree plot $^{29}$ (Figure 1). Item loadings were examined and presented for each factor, retaining those with loading greater than 0.3. Because the oblique rotation method allows the intercorrelation of the identified factors, their pairwise correlation matrix was also examined and presented. The derived factor scores were used along with the overall mean DES30-Sp score for further analyses.

The distribution of study covariates (overall and gender-stratified) was examined with simple proportions and descriptive statistics, as well as chisquare and Student's t tests. Mean overall DES30-Sp scores and standard errors (se) were computed across strata of gender and study year. The distribution of responses for each item and their mean scores were examined. To illustrate the perceived stress-provok- 
ing potential of all DES items among the participating students, the thirty items were ranked and presented in order of descending mean scores.

To examine the simultaneous association among demographic, socioeconomic, and dental studies-related factors on perceived stress, we generated a series of multi-level mixed-effects multiple linear regression models. In these models we specified three nested fixed-effect terms to account for the clustered $^{30}$ nature of data: geographic region (four levels), university/city (eleven levels), and school (seventeen levels). Models were a priori adjusted for gender, study year, and age. To allow for the examination of additional demographic and socioeconomic covariates, identical model specifications were used for the analyses of the mean DES score, as well as the four DES factors. Thus, covariates were included in the model if they showed nominal evidence of association $(p<0.05)$ with at least one of the five outcomes. Although inferences were not based on statistical hypothesis testing, the fitting of five multivariate models was accounted for with a Bonferroni correction resulting in a corrected pvalue significance threshold of 0.01 . Patterns and trends were further evaluated by predictive marginal means $^{31}$ and 95 percent confidence intervals (CI) of overall stress and factor scores that were generated after model-fitting, across study years, and stratified by variables of interest (gender, first career choice, etc.). The statistical software Stata 12.1 (StataCorp LP, College Station, TX) was used for all data analyses and the generation of figures.

\section{Results}

The mean age of the analytical sample $(n=5,636)$ was twenty-one years, and two-thirds of these students were females. The sample's descriptive information is shown in Table 1. Seventy percent of the students were in socioeconomic strata $1-3$, and 58 percent relied on their own funds for their education. Less than one out of five students worked while

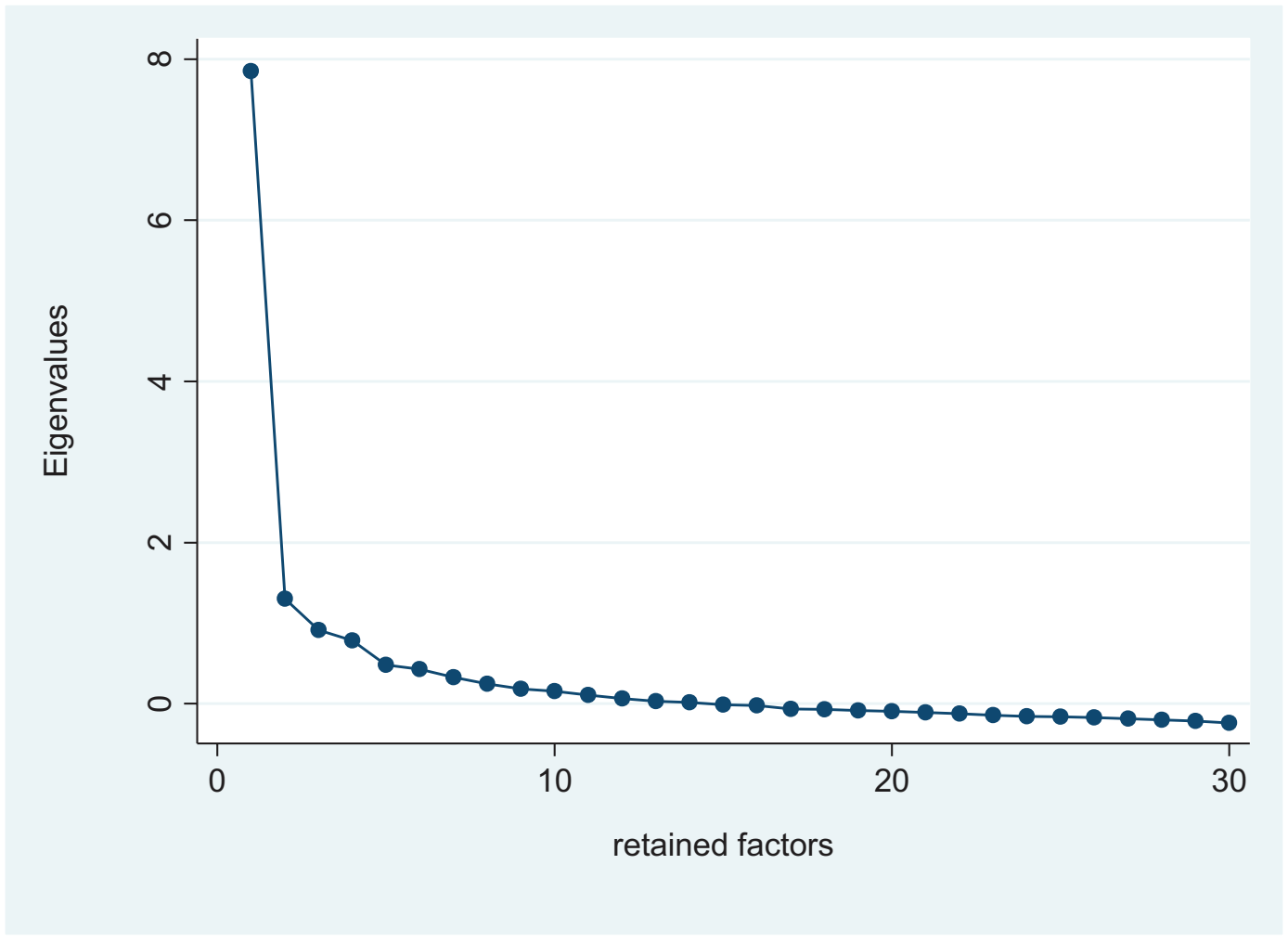

Figure 1. Scree plot of eigenvalues after principal factor analysis of DES30-Sp questionnaire among participating Colombian dental students $(n=5,636)$ 
Table 1. Demographic, socioeconomic, and dental studies information of the analytical sample $(n=5,636)$

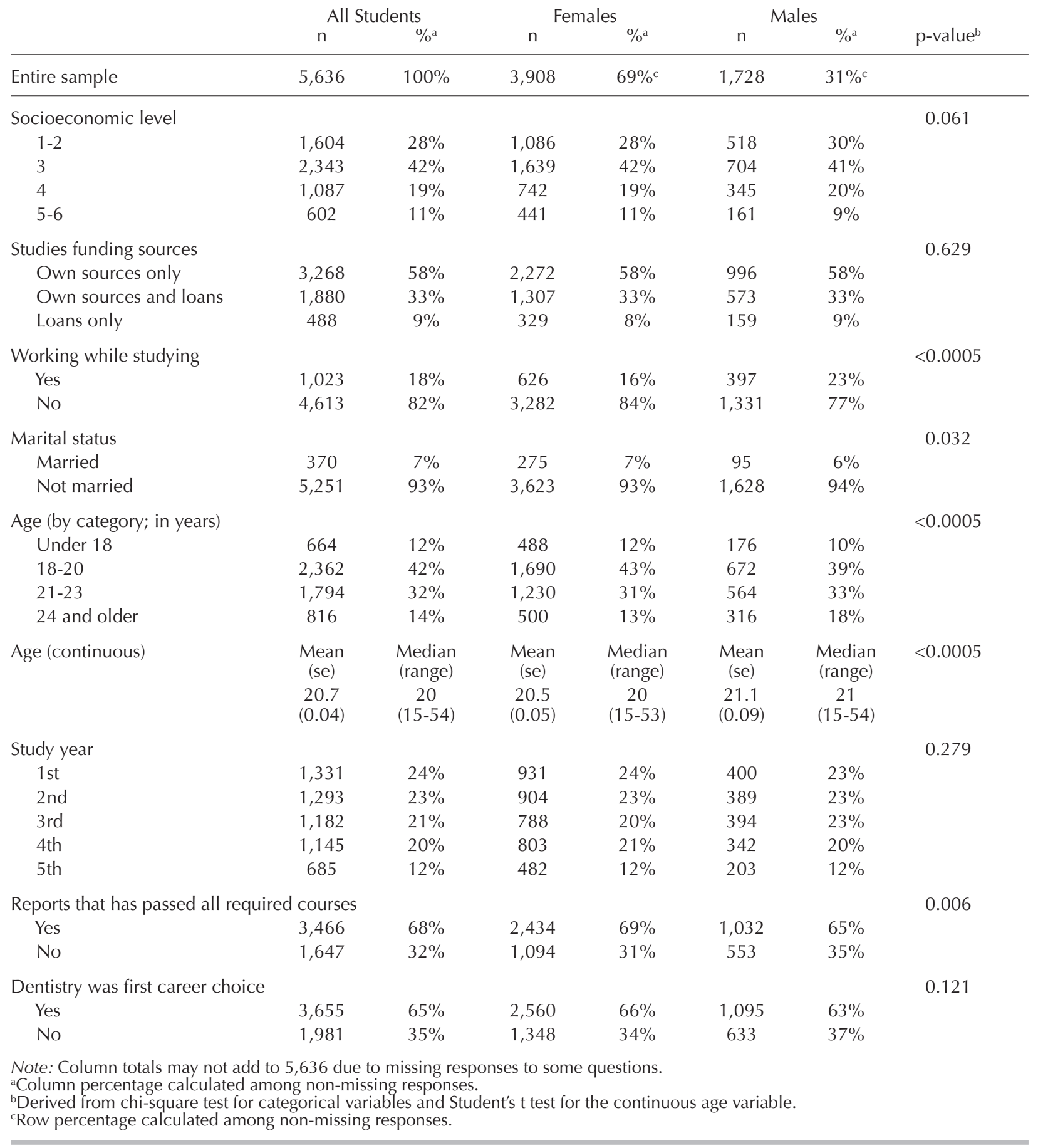

studying, and only 7 percent were married. Two-thirds reported that dentistry was their first career choice and that they have passed all required courses up to their study level. The number of participating students decreased from the first- to the fifth-year class; this attrition, however, was not different between males and females. Females, on the other hand, were on average six months younger than males and were less likely to work while studying, but more likely to report that they had passed all their required courses. Male students reported slightly lower overall mean stress (DES30-Sp) scores, 2.29 versus 2.40 
Table 2. DES30-Sp estimates, overall, and stratified by gender and study year, among participating Colombian dental students $(n=5,636)$

\begin{tabular}{lll} 
& $\begin{array}{c}\text { Females } \\
\text { Mean (se) }\end{array}$ & $\begin{array}{c}\text { Males } \\
\text { Mean (se) }\end{array}$ \\
\hline Entire sample & $2.40(0.01)$ & $2.29(0.01)$ \\
Study year & & \\
1st & $2.21(0.02)$ & $2.13(0.02)$ \\
2nd & $2.34(0.02)$ & $2.21(0.03)$ \\
3rd & $2.44(0.02)$ & $2.36(0.02)$ \\
4th & $2.59(0.02)$ & $2.41(0.03)$ \\
5th & $2.53(0.02)$ & $2.42(0.04)$
\end{tabular}

$\mathrm{se}=$ standard error of the mean among females - estimates that are both within the range of somewhat to quite stressful (Table 2). With only one exception (between years four and five among females), overall stress scores increased monotonically in each successive class for both genders. The highest ranked stress item was "fear of failing a course or a year," which was reported as very stressful by more than 60 percent of all students (Table 3). Other highly ranked items were "patients being late or not showing up for their appointments," "examinations and grades," and "lack of time for relaxation." The lowest ranked items were "lack of confidence to be a successful student," "lack of confidence to become a successful dentist," and "lack of home atmosphere in the living quarters."

Table 3. Mean DES30-Sp item scores, rank order, and responses in the analytical sample $(n=5,636)$

\begin{tabular}{|c|c|c|c|c|c|c|c|}
\hline \multirow{2}{*}{\multicolumn{2}{|c|}{ Stress Item }} & \multirow{2}{*}{$\begin{array}{l}\text { Item Mean Score } \\
\text { Mean }(95 \% \mathrm{Cl})\end{array}$} & \multirow[b]{2}{*}{ Rank } & \multicolumn{4}{|c|}{ Item Response } \\
\hline & & & & 1 & 2 & 3 & 4 \\
\hline$(24)$ & Fear of failing course or year & $3.32(3.29,3.34)$ & 1 & $7 \%$ & $14 \%$ & $18 \%$ & $61 \%$ \\
\hline (4) & Patients being late or not showing up for their appointments & $3.01(2.98,3.04)$ & 2 & $15 \%$ & $16 \%$ & $21 \%$ & $48 \%$ \\
\hline (5) & Examinations and grades & $3.01(2.98,3.03)$ & 3 & $6 \%$ & $23 \%$ & $36 \%$ & $35 \%$ \\
\hline (23) & Lack of time for relaxation & $2.90(2.87,2.93)$ & 4 & $11 \%$ & $26 \%$ & $25 \%$ & $38 \%$ \\
\hline (19) & Lack of time to do assigned school work & $2.70(2.68,2.73)$ & 5 & $12 \%$ & $31 \%$ & $31 \%$ & $26 \%$ \\
\hline (27) & $\begin{array}{l}\text { Fear of dealing with patients who non-disclose the existence of } \\
\text { a contagious disease }\end{array}$ & $2.68(2.65,2.71)$ & 6 & $17 \%$ & $28 \%$ & $27 \%$ & $29 \%$ \\
\hline$(12)$ & Lack of time between seminars and laboratories or clinics & $2.64(2.61,2.66)$ & 7 & $15 \%$ & $31 \%$ & $30 \%$ & $24 \%$ \\
\hline (3) & Competition for grades & $2.57(2.54,2.59)$ & 8 & $15 \%$ & $32 \%$ & $34 \%$ & $19 \%$ \\
\hline (15) & Completing graduation rec & $2.48(2.45,2.51)$ & 9 & $25 \%$ & $27 \%$ & $23 \%$ & $25 \%$ \\
\hline (26) & Neglect for personal life & $2.46(2.44,2.49)$ & 10 & $21 \%$ & $32 \%$ & $28 \%$ & $20 \%$ \\
\hline (6) & Atmosphere created by clinica & $2.45(2.42,2.48)$ & 11 & $21 \%$ & $33 \%$ & $26 \%$ & $20 \%$ \\
\hline (18) & Financial responsibilities & $2.45(2.42,2.48)$ & 12 & $25 \%$ & $28 \%$ & $23 \%$ & $24 \%$ \\
\hline$(22)$ & Lack of communication or cooperati & $2.32(2.30,2.35)$ & 13 & $26 \%$ & $32 \%$ & $24 \%$ & $17 \%$ \\
\hline (30) & Cooperation with dental laboratory & $2.29(2.26,2.32)$ & 14 & $28 \%$ & $32 \%$ & $23 \%$ & $17 \%$ \\
\hline (1) & Amount of assigned class work & $2.28(2.26,2.31)$ & & $15 \%$ & $51 \%$ & $25 \%$ & $9 \%$ \\
\hline$(28)$ & Delay of receiving textbooks or course notes & $2.28(2.26,2.31)$ & 16 & $23 \%$ & $39 \%$ & $25 \%$ & $13 \%$ \\
\hline$(25)$ & Working while studying & $2.27(2.24,2.30)$ & 17 & $41 \%$ & $16 \%$ & $18 \%$ & $25 \%$ \\
\hline$(2)$ & Difficulty of class work & $2.24(2.22,2.26)$ & 18 & $15 \%$ & $53 \%$ & $26 \%$ & $6 \%$ \\
\hline (9) & Lack of adequate clinical st & $2.23(2.20,2.26)$ & 19 & $30 \%$ & $34 \%$ & $21 \%$ & $16 \%$ \\
\hline (20) & Inconsistency of feedback on work between different instructors & $2.22(2.19,2.24)$ & 20 & $21 \%$ & $47 \%$ & $23 \%$ & $10 \%$ \\
\hline$(17)$ & Insecurity concerning professional future & $2.20(2.17,2.23)$ & 21 & $30 \%$ & $34 \%$ & $22 \%$ & $14 \%$ \\
\hline (7) & $\begin{array}{l}\text { Difficulty in learning precision manual skills required in } \\
\text { preclinical and laboratory work }\end{array}$ & $2.10(2.07,2.12)$ & 22 & $29 \%$ & $41 \%$ & $20 \%$ & $9 \%$ \\
\hline (13) & Rules and regulations of the school & $2.09(2.06,2.12)$ & 23 & $34 \%$ & $35 \%$ & $19 \%$ & $12 \%$ \\
\hline (16) & Lack of input in the decision making process of the school & $2.05(2.03,2.08)$ & 24 & $34 \%$ & $38 \%$ & $18 \%$ & $11 \%$ \\
\hline$(21)$ & Attendance and success in medical subjects & $2.02(2.00,2.05)$ & 25 & $32 \%$ & $41 \%$ & $20 \%$ & $7 \%$ \\
\hline (8) & Difficulty in learning clinical procedures and pr & $2.02(1.99,2.04)$ & 26 & $31 \%$ & $43 \%$ & $19 \%$ & $7 \%$ \\
\hline$(29)$ & Lack of self-assessment and awareness of own competence & $2.00(1.98,2.02)$ & 27 & $31 \%$ & $43 \%$ & $19 \%$ & $6 \%$ \\
\hline (10) & Lack of confidence to be a successful student & $1.97(1.94,1.99)$ & 28 & $38 \%$ & $36 \%$ & $17 \%$ & $9 \%$ \\
\hline (11) & Lack of confidence in self to be a successful dentist & $1.93(1.90,1.95)$ & 29 & $41 \%$ & $35 \%$ & $15 \%$ & $9 \%$ \\
\hline$(14)$ & Lack of home atmosphere in the living quarters & $1.88(1.85,1.90)$ & 30 & $50 \%$ & $23 \%$ & $15 \%$ & $12 \%$ \\
\hline
\end{tabular}

Note: Item responses on scale of $1=$ not stressful at all, $2=$ somewhat stressful, $3=$ quite stressful, $4=$ very stressful. Numbers in parentheses with items refer to each item's number in the DES30-Sp questionnaire. $\mathrm{Cl}$ : confidence interval 
The factor analysis with oblique rotation confirmed the presence of four main factors (Figure 1). Item loadings with a value greater than 0.3 are shown for each factor in Table 4. Factor 1 was dominated by clinical training items such as "patients being late," "atmosphere created by clinical faculty," and "lack of adequate clinical staff in the clinics." Items loading on Factor 2 pertained mostly to time constraints, Factor 3 to workload, and Factor 4 to self-efficacy beliefs. All factors were pairwise significantly correlated, with the highest correlations being between clinical training and workload (Table 5).

The multivariate models for overall perceived stress and the four DES factors included (beyond age, gender, and class) terms for "marital status," "passed all subjects," "socioeconomic status," "reliance on financial support," "working while studying," and dentistry was "first career choice" (Table 6). Males had lower adjusted stress scores throughout the entire course of studies. "Having dentistry as first career choice" also showed an association with stress, but this was mostly evident in the fourth and fifth years (Figure 2). Similarly, and adjusting for all other covariates, dentistry as first career choice was consistently associated with lower scores in the four stress factor domains. Figure 3 illustrates the by-study year adjusted model predictions (marginal means) of factor scores for male and female students. Notably, a frank positive gradient was found for clinical training, whereas the patterns for the other factors were less clear. For instance, workload appeared to peak between years three and four and decrease in the fifth year.

Belonging to a higher socioeconomic stratum was associated with lower stress scores, with the exception of the workload domain, where the inverse

Table 4. Four-factor solution and item loadings derived from iterated principal factor analysis with promax (oblique) rotation of thirty DES30-Sp stressors among participating Colombian dental students $(n=5,636)$

\begin{tabular}{|c|c|c|c|c|c|}
\hline Item \# & Factor 1 & Factor 2 & Factor 3 & Factor 4 & Uniqueness \\
\hline 1 & & & 0.712 & & 0.587 \\
\hline 2 & & & 0.628 & & 0.614 \\
\hline 3 & & & 0.339 & & 0.766 \\
\hline 4 & 0.682 & & & & 0.618 \\
\hline 5 & & & 0.429 & & 0.673 \\
\hline 6 & 0.595 & & & & 0.581 \\
\hline 7 & & & & 0.448 & 0.638 \\
\hline 8 & & & & 0.442 & 0.602 \\
\hline 9 & 0.588 & & & & 0.645 \\
\hline 10 & & & & 0.806 & 0.373 \\
\hline 11 & & & & 0.837 & 0.326 \\
\hline 12 & 0.356 & & & & 0.613 \\
\hline 13 & 0.517 & & & & 0.685 \\
\hline 14 & & & & & 0.879 \\
\hline 15 & 0.568 & & & & 0.598 \\
\hline 16 & 0.511 & & & & 0.656 \\
\hline 17 & & & & 0.356 & 0.655 \\
\hline 18 & & 0.328 & & & 0.746 \\
\hline 19 & & 0.345 & 0.403 & & 0.563 \\
\hline 20 & & & & & 0.634 \\
\hline 21 & & & & & 0.642 \\
\hline 22 & 0.533 & & & & 0.626 \\
\hline 23 & & 0.367 & & & 0.626 \\
\hline 24 & & & & & 0.749 \\
\hline 25 & & 0.492 & & & 0.784 \\
\hline 26 & & 0.604 & & & 0.586 \\
\hline 27 & & 0.440 & & & 0.738 \\
\hline 28 & & 0.579 & & & 0.653 \\
\hline 29 & & 0.518 & & & 0.625 \\
\hline 30 & 0.412 & & & & 0.641 \\
\hline Variance & 6.3 & 5.4 & 4.6 & 4.3 & \\
\hline
\end{tabular}




\begin{tabular}{lccc}
$\begin{array}{l}\text { Table 5. Pairwise correlations among four DES30-Sp factors in analytical sample }(\mathbf{n = 5 , 6 3 6 )} \\
\text { DES30-Sp Factor }\end{array}$ & F1: Clinical Training & F2: Time Constraints & F3: Workload \\
\hline F2: Time constraints & 0.406 & 1.000 & 1.000 \\
F3: Workload & 0.419 & 0.309 & 0.311 \\
F4: Self-efficacy beliefs & 0.355 & 0.321 &
\end{tabular}

Table 6. Results of multi-level multivariate linear regression modeling of overall DES30-Sp score and four DES factors on demographic, socioeconomic, and dental studies-related factors

\begin{tabular}{|c|c|c|c|c|c|c|c|c|c|c|}
\hline \multirow[b]{3}{*}{ Independent Variable } & \multirow{2}{*}{\multicolumn{2}{|c|}{$\begin{array}{l}\text { Perceived Stress } \\
\text { Mean DES30 }\end{array}$}} & \multicolumn{8}{|c|}{ DES30-Sp Stress Factor Domains } \\
\hline & & & \multicolumn{2}{|c|}{ Clinical Training } & \multicolumn{2}{|c|}{ Time Constraints } & \multicolumn{2}{|c|}{ Workload } & \multicolumn{2}{|c|}{ Self-Efficacy } \\
\hline & beta & $\mathrm{p}$ & beta & $p$ & beta & $\mathrm{p}$ & beta & $\mathrm{p}$ & beta & $\mathrm{p}$ \\
\hline Gender (male) & -0.07 & $<0.001$ & -0.06 & 0.036 & -0.13 & 0.001 & -0.05 & 0.201 & -0.12 & 0.001 \\
\hline Age (years) & 0.00 & 0.912 & 0.00 & 0.989 & 0.01 & 0.097 & -0.02 & 0.005 & 0.00 & 0.926 \\
\hline Marital status (married) & 0.07 & 0.012 & 0.11 & 0.061 & 0.21 & 0.004 & 0.07 & 0.059 & -0.02 & 0.733 \\
\hline \multicolumn{11}{|l|}{ Class (ref: 1 st year) } \\
\hline 2 nd & 0.06 & 0.003 & 0.20 & $<0.001$ & -0.14 & 0.015 & 0.17 & 0.003 & 0.08 & 0.131 \\
\hline $3 r d$ & 0.18 & $<0.001$ & 0.65 & $<0.001$ & -0.07 & 0.209 & 0.33 & $<0.001$ & -0.04 & 0.523 \\
\hline 4th & 0.31 & $<0.001$ & 1.10 & $<0.001$ & 0.15 & 0.016 & 0.36 & $<0.001$ & -0.01 & 0.901 \\
\hline 5 th & 0.28 & $<0.001$ & 1.13 & $<0.001$ & 0.03 & 0.663 & 0.17 & 0.015 & -0.10 & 0.144 \\
\hline $\begin{array}{l}\text { Reports that has passed all } \\
\text { courses }\end{array}$ & 0.00 & 0.797 & 0.02 & 0.504 & 0.02 & 0.594 & 0.07 & 0.059 & -0.10 & 0.005 \\
\hline Socioeconomic status & -0.01 & 0.068 & -0.01 & 0.417 & -0.07 & $<0.001$ & 0.05 & 0.009 & -0.03 & 0.106 \\
\hline $\begin{array}{l}\text { Reliance on financial support } \\
\text { (ref: no) }\end{array}$ & 0.05 & $<0.001$ & 0.05 & 0.036 & 0.07 & 0.005 & 0.13 & $<0.001$ & 0.00 & 0.992 \\
\hline $\begin{array}{l}\text { Working while studying } \\
\text { (ref: no) }\end{array}$ & -0.02 & 0.249 & -0.11 & 0.002 & 0.07 & 0.105 & -0.09 & 0.051 & -0.13 & 0.002 \\
\hline $\begin{array}{l}\text { Dentistry was first career } \\
\text { choice (ref: no) }\end{array}$ & -0.04 & 0.001 & -0.08 & 0.008 & -0.04 & 0.242 & -0.04 & 0.235 & -0.08 & 0.030 \\
\hline
\end{tabular}

Note: The multi-level model included three nested random effect terms accounting for the clustering of observations within school, university, and geographical region.

association was noted. Reliance on financial support was associated with higher stress, except for the domain of self-efficacy, where there was virtually no association. Inversely, having passed all required courses did not show any association except with self-efficacy beliefs, where it had a protective effect. Finally, "working while studying" showed a favorable association with stress reports in the domains of clinical training and self-efficacy beliefs.

\section{Discussion}

This study represents the first large-scale investigation of dental students' perceived stressors and their extracurricular correlates in Latin America, us- ing a cross-culturally adapted instrument. The study's findings provide insights into the main concerns of this group of students regarding their education, offering potential targets for intervention. Importantly, these data provide a novel insight into factors affecting or modifying dental students' experiences while in dental school. Specifically, this study demonstrates that, above and beyond traditional parameters of the academic environment, distal factors, including demographic, socioeconomic, and career choice, are important and independent determinants of perceived stress. The finding of an independent association of predoctoral dental students' socioeconomic level with perceived stress represents, to the best of our knowledge, a novel finding. 

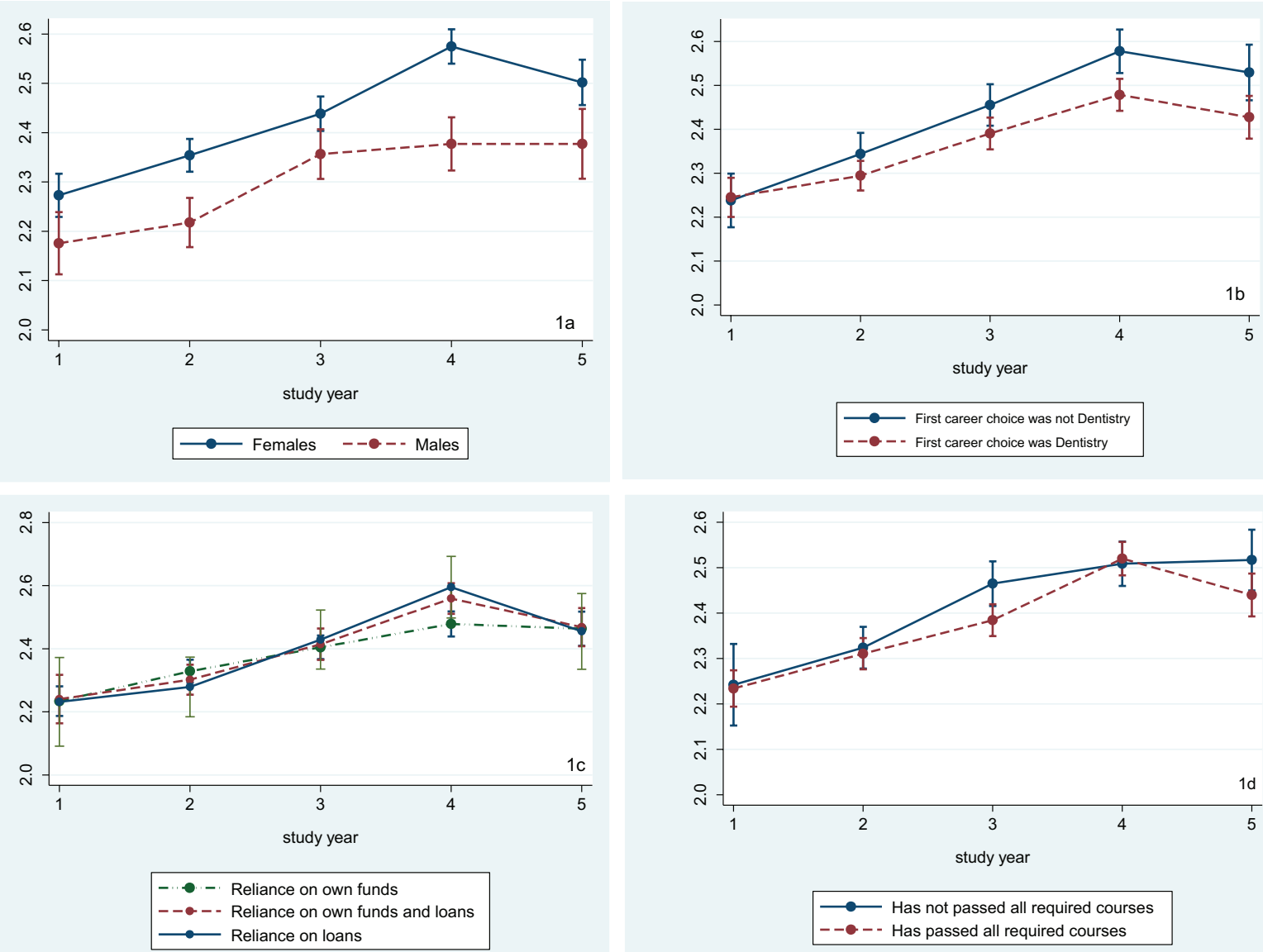

Figure 2. Model-predicted overall stress (DES30-Sp) scores and 95\% confidence intervals $(\mathrm{Cl})$ across study years among participating Colombian dental students $(n=5,636)$

Note: Model for strata of: $1 \mathrm{a}=$ gender, $1 \mathrm{~b}=$ dentistry as a first career choice, $1 \mathrm{c}=$ funding sources of dental studies, and $1 \mathrm{~d}=$ =report of having passed all required courses. The multivariate mixed-effects model accounted for clustering of observations within schools, cities/ universities, and geographic regions and included terms for age, gender, socioeconomic status, marital status, funding sources, working while studying, having passed all required courses, and having dentistry as first career choice.

The results of this investigation are consistent with previous studies examining students' concerns and stressors in the dental education environment. In fact, "fear of failing a course or a year" was the top stressor among groups of Chilean, Argentinean, ${ }^{22}$ Australian, ${ }^{32}$ and Turkish students; $; 3$ "examinations and grades" among North American, ${ }^{26}$ Canadian, ${ }^{34}$ Indian, ${ }^{35}$ and Bulgarian students; ${ }^{36}$ and "patients being later or not showing up for their appointments" among Saudi Arabian students. ${ }^{37}$ Furthermore, "academic workload" emerged as the main concern in a recent qualitative study of Colombian dental students at the University of Antioquia. ${ }^{38}$ The fact that dental students' concerns in diverse settings are convergent is not surprising and highlights the common themes that require attention in dental education. ${ }^{4}$ For example, emphasis on formative versus summative assessments, elimination of quotas, problem-based learning, and reflective portfolios are some strategies that have shown promise. . $^{24,39,40}$

Students belonging to lower socioeconomic strata and relying on loan support demonstrated higher perceived stress in most domains compared to those in higher strata and using own funds, independent of other curricular and sociodemographic factors. This is a novel and important finding, demonstrating how external pressures and extracurricular factors may influence the way students interpret and 

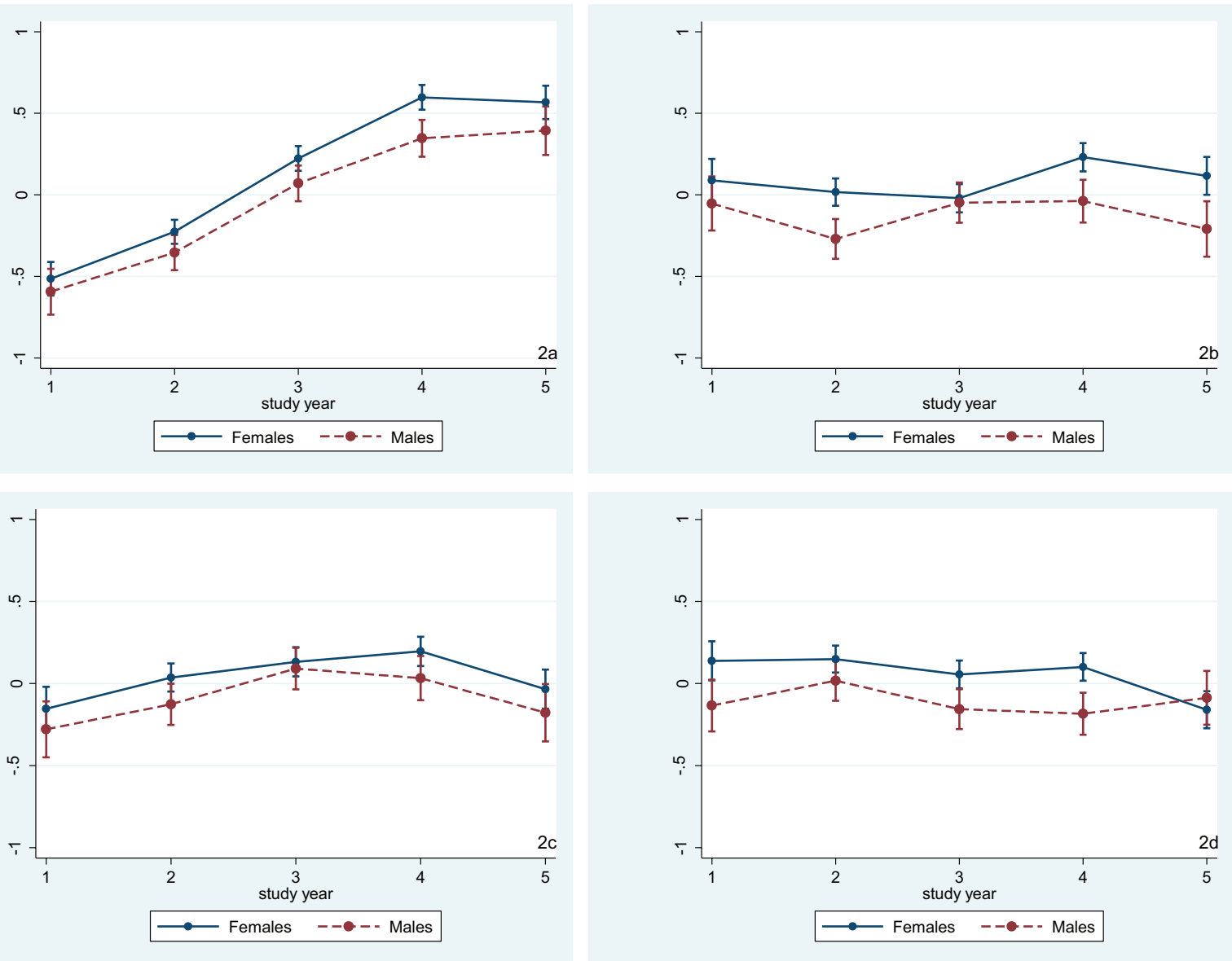

Figure 3. Model-predicted DES30-Sp stress factor scores (centered to 0) and 95 percent confidence intervals (Cl) among Colombian dental students $(n=5,636)$ stratified by gender

Note: $2 \mathrm{a}=$ clinical training, $2 \mathrm{~b}=$ time constraints, $2 \mathrm{c}=$ workload, and $2 \mathrm{~d}=$ self-efficacy beliefs. The multivariate mixed-effects model accounted for clustering of observations within schools, cities/universities and geographic regions and included terms for age, gender, socioeconomic status, marital status, funding sources, working while studying, having passed all required courses, and having dentistry as first career choice.

experience their dental education environment. The link between lower socioeconomic background and higher levels of psychological distress was evident in earlier studies among British university students by Roberts et al. ${ }^{41}$ and a large group of university students from twenty-three countries. ${ }^{42}$ Similar findings were reported by Omigbodun et al., ${ }^{43}$ who examined stressors and psychological symptoms among health science students in Nigeria and found an association between financial problems and perceived stress. In contrast, Verger et $a 1 .{ }^{44}$ did not find any important association between socioeconomics and perceived stress among first-year French university students; however, in that study the investigators used "grant or scholarship support" as a binary proxy of socioeconomic status, which as they noted "may not suffice to assess the socioeconomic inequalities among students." Interestingly, being in lower socioeconomic strata in our study was associated with significantly decreased stress regarding workload, indicating a complex association. Moreover, "working while studying" showed a favorable association and decreased stress perceptions regarding clinical training and self-efficacy; it is unclear, however, from the data that were collected in our study whether this parallel employment was related to dentistry or not.

Students' career choice showed a frank "protective" association with regard to perceived stress in 
all domains. Interestingly, this association was virtually absent at dental school entry among first-year students but was pronounced in subsequent years, presumably after prolonged exposure to the stresses of preclinical and clinical dental training. This is in agreement with previous evidence of higher stress among students whose first career choice was not dentistry in Japan ${ }^{19}$ and Nigeria ${ }^{45}$ as well as among students who were dissatisfied ${ }^{46}$ or reported parental pressures in making a career choice. ${ }^{47}$ Taken together, these data suggest that dental students whose first career was not dentistry may be more prone to perceive certain aspects of dental training as more stressful than their peers and thus may be more vulnerable for development of burnout and psychological morbidity. ${ }^{12,48}$ Efforts to prevent or alleviate such negative consequences might include counseling, peer support, and mentoring services. ${ }^{49-51}$

Female students demonstrated consistently higher levels of perceived stress among the examined cohort of predoctoral dental students. This difference was small in magnitude; however, it persisted after adjustment for an array of socioeconomic and dental studies-related factors. Different reasons may lie behind this observation: females may actually perceive and experience more stress, males may be less expressive of their concerns, or there is a combination of these or other unknown and unmeasured factors. Notably, the largest-in-magnitude gender differences in this study were noted in the domains of time constraints and self-efficacy beliefs. Findings in the literature are mixed on this topic; some investigators have found higher perceived stress among females, ${ }^{33,19,46,52}$ others among males, ${ }^{47,53}$ and others found no difference. ${ }^{45,54}$ Sociocultural factors are sometimes cited ${ }^{24,36}$ and may account for the different results in these studies; nevertheless, it is important that this issue continues to be monitored $^{9}$ to ensure an equitable and accommodating academic environment for all students.

This study's findings must be regarded in view of its limitations. Due to its cross-sectional nature, this investigation is limited with regard to making robust inferences by study year. However, the results of a longitudinal cohort and a cross-sectional study that were both conducted among the same student sample provided similar results, indicating the absence of strong cohort effects. ${ }^{52}$ In the present study, however, substantial attrition was noted, with the number of fifth-year students in the sample being nearly half of that of first-year students. It is not possible to impute or infer the stress levels of non- respondents, but it may be plausible to suggest that those who did not respond or had dropped out of the school may comprise a special "vulnerable" group of students. Moreover, this study did not collect any information on students' personality characteristics, such as personality type, emotional intelligence, or general self-efficacy, which have been shown to buffer or alleviate stress manifestations.

It must be acknowledged that most of the differences in stress levels that were found were small in magnitude, in the range of 0.1 to 0.3 on a 4.0 point scale. Reliance on statistical significance testing using large samples, as the present one, may result in misleading impressions regarding the importance of certain differences and risk factors. For this reason, caution was exercised in avoiding interpretation of the study findings from a statistical perspective alone. Moreover, it can be argued that differences in Colombian students' demography and admissions procedures (predoctoral dental students tend to be younger due to the dental school admissions offered after high school graduation), as well as in the country's sociocultural and economic environment may limit the potential to generalize these findings to other student populations. Finally, this study examined the perceived stress-provoking potential of certain dental environment items rather than clinically manifested stress or psychological morbidity and symptoms. The use of additional endpoints, such as clinically validated instruments and possibly biomarkers, ${ }^{55-57}$ in future studies would certainly offer a more comprehensive understanding of dental students' stress experiences.

It is expected that participating institutions will benefit from introspection based on individual dental school reports that will emanate from this survey. Strategies for improvements may include the identification of vulnerable individuals and eventually systemic changes that render the dental school environment less stress-provoking and more accommodating to individual characteristics. Based on this study's findings, students whose first career choice was not dentistry, who are relying on financial support, and who are from low socioeconomic strata may benefit from early mentoring and counseling services upon dental school admission. In a recent study among French third-year students, Neveu et al. ${ }^{58}$ found that personal and environmental risk factors and students' coping strategies modified the association between programmatic factors and perceived stress. This is in line with Dunn et al.'s conceptual model for promoting resilience and preventing burnout, wherein 
emphasis on the positive aspects of training and capitalization on students' "coping reservoirs" can help promote students' educational and professional well-being. ${ }^{59}$ Dental programs should adopt a positive pedagogical ethos and reach beyond being reactive to and merely accommodating to dental students' concerns; instead, it is warranted that they develop the agility to be proactive and prevent burnout by fostering a positive academic environment.

\section{Acknowledgments}

This study was supported by funding from the Comité Nacional para el Desarrollo de la Investigación (CONADI) of Universidad Cooperativa de Colombia, the División de Investigación Asociación Colombiana de Facultades de Odontología, and by study infrastructure support from all participating institutions.

\section{REFERENCES}

1. Iacopino AM. The influence of "new science" on dental education: current concepts, trends, and models for the future. J Dent Educ 2007;71(4):450-62.

2. Henzi D, Davis E, Jasinevicius R, et al. Appraisal of the dental school learning environment: the students' view. J Dent Educ 2005;69(10):1137-47.

3. Henzi D, Davis E, Jasinevicius R, Hendricson W. In the students' own words: what are the strengths and weaknesses of the dental school curriculum? J Dent Educ 2007;71(5):632-45.

4. Divaris K, Barlow PJ, Chendea SA, et al. The academic environment: the students' perspective. Eur J Dent Educ 2008;12(Suppl 1):120-30.

5. Pau AK, Croucher R, Sohanpal R, et al. Emotional intelligence and stress coping in dental undergraduates: a qualitative study. Br Dent J 2004;197(4):205-9.

6. Dahan H, Bedos C. A typology of dental students according to their experience of stress: a qualitative study. J Dent Educ 2010;74(2):95-103.

7. Humphris G, Blinkhorn A, Freeman R, et al. Psychological stress in undergraduate dental students: baseline results from seven European dental schools. Eur J Dent Educ 2002;6(1):22-9.

8. Pöhlmann K, Jonas I, Ruf S, Harzer W. Stress, burnout, and health in the clinical period of dental education. Eur J Dent Educ 2005;9(2):78-84.

9. Gorter RC, Storm MK, te Brake JH, et al. Outcome of career expectancies and early professional burnout among newly qualified dentists. Int Dent J 2007;57(4):279-85.

10. Gorter R, Freeman R, Hammen S, et al. Psychological stress and health in undergraduate dental students: fifthyear outcomes compared with first-year baseline results from five European dental schools. Eur J Dent Educ 2008;12(2):61-8.

11. Henning K, Ey S, Shaw D. Perfectionism, the imposter phenomenon, and psychological adjustment in medi- cal, dental, nursing, and pharmacy students. Med Educ 1998;32(5):456-64.

12. George JM, Whitworth DE, Sturdevant JR, Lundeen TF. Correlates of dental student stress. J Dent Educ 1987;51(8):481-5.

13. Sturdevant JR, George JM, Lundeen TF. An interactional view of dental student stress. J Dent Educ 1987;51(5): 246-9.

14. Stewart DW, de Vries J, Singer DL, et al. Canadian dental students' perceptions of their learning environment and psychological functioning over time. J Dent Educ 2006;70(9):972-81.

15. Muirhead V, Locker D. Canadian dental students' perceptions of stress and social support. Eur J Dent Educ 2008;12(3):144-8.

16. Schéle IA, Hedman LR, Hammarström A. A model of psychosocial work environment, stress, and satisfaction among dental students in Sweden. J Dent Educ 2012;76(9):1206-17.

17. Alzahem AM, van der Molen HT, Alaujan AH, et al. Stress amongst dental students: a systematic review. Eur J Dent Educ 2011;15(1):8-18.

18. Pau A, Rowland ML, Naidoo S, et al. Emotional intelligence and perceived stress in dental undergraduates: a multinational survey. J Dent Educ 2007;71(2):197-204.

19. Sugiura G, Shinada K, Kawaguchi Y. Psychological wellbeing and perceptions of stress amongst Japanese dental students. Eur J Dent Educ 2005;9(1):17-25.

20. Gallo LC, Matthews KA. Understanding the association between socioeconomic status and physical health: do negative emotions play a role? Psychol Bull 2003;129(1): 10-51.

21. Divaris K, Mafla AC, Villa-Torres L, et al. Psychological distress and its correlates among dental students: a survey of 17 Colombian dental schools. BMC Med Educ 2013;13:91.

22. Fonseca J, Divaris K, Villalba S, et al. Perceived sources of stress amongst Chilean and Argentinean dental students. Eur J Dent Educ 2013;17(1):30-8.

23. Polychronopoulou A, Divaris K. Perceived sources of stress among Greek dental students. J Dent Educ 2005;69(6):687-92.

24. Polychronopoulou A, Divaris K. Dental students' perceived sources of stress: a multi-country study. J Dent Educ 2009;73(5):631-9.

25. Garbee WH Jr, Zucker SB, Selby GR. Perceived sources of stress among dental students. J Am Dent Assoc 1980;100(6):853-7.

26. Westerman GH, Grandy TG, Ocanto RA, Erskine CG. Perceived sources of stress in the dental school environment. J Dent Educ 1993;57(3):225-31.

27. Schafer JL, Recai MY. Computational strategies for multivariate linear mixed-effects models with missing values. J Computational Graphical Stat 2002;11(2):437-57.

28. Hendrickson AE, White PO. Promax: a quick method for rotation to oblique simple structure. Br J Stat Psychol 1964;17(1):65-70.

29. Cattell RB. The scree test for the number of factors. Multivariate Behav Res 1966;1(2):245-76.

30. Fleming PS, Koletsi D, Polychronopoulou A, et al. Are clustering effects accounted for in statistical analysis in 
leading dental specialty journals? J Dent 2013;41(3): 265-70.

31. Graubard BI, Korn EL. Predictive margins with survey data. Biometrics 2004;55(2):652-9.

32. Sanders AE, Lushington K. Sources of stress for Australian dental students. J Dent Educ 1999;63(9):688-97.

33. Peker I, Alkurt MT, Usta MG, Turkbay T. The evaluation of perceived sources of stress and stress levels among Turkish dental students. Int Dent J 2009;59(2):103-11.

34. Muirhead V, Locker D. Canadian dental students' perceptions of stress. J Can Dent Assoc 2007;73(4):323.

35. Kumar S, Dagli RJ, Mathur A, et al. Perceived sources of stress amongst Indian dental students. Eur J Dent Educ 2009;13(1):39-45.

36. Manolova MS, Stefanova VP, Panayotov IV, et al. Perceived sources of stress in fifth-year dental students: a comparative study. Folia Med (Plovdiv) 2012;54(2):52-9.

37. Al-Saleh SA, Al-Madi EM, Al-Angari NS, et al. Survey of perceived stress-inducing problems among dental students, Saudi Arabia. Saudi Dent J 2010;22(2):83-8.

38. Jaramillo G, Caro H, Gómez Parra ZA, et al. [Stress and triggering devices in dental students of Universidad de Antioquia]. Rev Fac Odontol Univ Antioq 2008;20(1):4957. [In Spanish]

39. Dodge WW, Dale RA, Hendricson WD. A preliminary study of the effect of eliminating requirements on clinical performance. J Dent Educ 1993;57(9):667-72.

40. Albino JE, Young SK, Neumann LM, et al. Assessing dental students' competence: best practice recommendations in the performance assessment literature and investigation of current practices in predoctoral dental education. J Dent Educ 2008;72(12):1405-35.

41. Roberts R, Golding J, Towell T, Weinreb I. The effects of economic circumstances on British students' mental and physical health. J Am Coll Health 1999;48(3):103-9.

42. Steptoe A, Tsuda A, Tanaka Y, Wardle J. Depressive symptoms, socioeconomic background, sense of control, and cultural factors in university students from 23 countries. Int J Behav Med 2007;14(2):97-107.

43. Omigbodun OO, Odukogbe AT, Omigbodun AO, et al. Stressors and psychological symptoms in students of medicine and allied health professions in Nigeria. Soc Psychiatry Psychiatr Epidemiol 2006;41(5):415-21.

44. Verger P, Combes JB, Kovess-Masfety V, et al. Psychological distress in first year university students: socioeconomic and academic stressors, mastery, and social support in young men and women. Soc Psychiatry Psychiatr Epidemiol 2009;44(8):643-50.

45. Sofola OO, Jeboda SO. Perceived sources of stress in Nigerian dental students. Eur J Dent Educ 2006;10(1):20-3.

46. Naidoo S, Pau A. Emotional intelligence and perceived stress. SADJ 2008;63(3):148-51.

47. Acharya S. Factors affecting stress among Indian dental students. J Dent Educ 2003;67(10):1140-8.

48. Preciado ML, Vázquez JM. [Stress profile and burnout syndrome in Mexican dental students of a public university]. Rev chil neuro-psiquiatr 2010;48(1):11-9. [In Spanish]

49. Peterson U, Bergström G, Samuelsson M, et al. Reflecting peer-support groups in the prevention of stress and burnout: randomized controlled trial. J Adv Nurs 2008;63(5):506-16.

50. Iversen A, Rushforth B, Forrest K. How to handle stress and look after your mental health. BMJ 2009;338:b1368.

51. Jacob T, Itzchak EB, Raz O. Stress among health care students: a cross-disciplinary perspective. Physiother Theory Prac 2012;24:1-12.

52. Polychronopoulou A, Divaris K. A longitudinal study of Greek dental students' perceived sources of stress. J Dent Educ 2010;74(5):524-30.

53. Tangade PS, Mathur A, Gupta R, Chaudhary S. Assessment of stress level among dental school students: an Indian outlook. Dent Res J (Isfahan) 2011;8(2):95-101.

54. Murphy RJ, Gray SA, Sterling G, et al. A comparative study of professional student stress. J Dent Educ 2009;73(3):328-37.

55. Ng V, Koh D, Mok BY, et al. Salivary biomarkers associated with academic assessment stress among dental undergraduates. J Dent Educ 2003;67(10):1091-4.

56. Ng V, Koh D, Mok B, et al. Stressful life events of dental students and salivary immunoglobulin A. Int J Immunopathol Pharmacol 2004;17(2 Suppl):49-56.

57. Pani SC, Al Askar AM, Al Mohrij SI, Al Ohali TA. Evaluation of stress in final-year Saudi dental students using salivary cortisol as a biomarker. J Dent Educ 2011;75(3):377-84.

58. Neveu D, Doron J, Visier L, et al. Students-perceived stress in academic programs: consequences for its management. Rev Epidemiol Sante Publique 2012;60(4):255-64.

59. Dunn LB, Iglewicz A, Moutier C. A conceptual model of medical student well-being: promoting resilience and preventing burnout. Acad Psychiatry 2008;32(1):44-53. 